\title{
Experimental Right Ventriculotomy: Effects on Local Propagation at a Small Size Scale
}

\author{
JEFFREY P. MOAK AND ARTHUR GARSON, JR. \\ The Lillie Frank Abercrombie Section of Cardiology, Department of Pediatrics, Baylor College of Medicine and \\ Texas Children's Hospital, Houston, Texas 77030
}

\begin{abstract}
Repair of tetralogy of Fallot and ventricular septal defect frequently requires righ ventriculotomy. Although the mechanisms for right bundle branch block (RBBB) have been frequently discussed, the pathogenesis of this electrocardiographic abnormality is still unknown. To determine if disruption of the distal subendocardial Purkinje fiber network in the right ventricular free wall produced RBBB and if cellular electrophysiologic abnormalities in or near the ventriculotomy scar could provide a substrate for conductance disturbances, we investigated the electrocardiographic and electrophysiologic effects of experimental right ventriculotomy in 12 beagles. On the surface electrocardiogram no significant differences in QRS duration (lead II) or morphology were apparent between the control group $(n=6)$ and the postventriculotomy animals $(n=6)(\mathrm{QRS}$ duration $=34 \pm 4$ versus $34 \pm 7$ $\mathrm{ms}$, respectively). Using microelectrode techniques, the right ventricular endocardial surface was carefully mapped. To facilitate analysis, data were grouped into five regions: outflow septum, outflow free wall, inflow free wall, and ventriculotomy region. No significant delays of regional activation were noted in the postventriculotomy group compared to the control group: outflow septum $-30 \pm 16$ versus $36 \pm 16 \mathrm{~ms}$; outflow free wall- $33 \pm 10$ versus $38 \pm 19$ $\mathrm{ms}$, inflow septum-32 \pm 7 versus $33 \pm 13 \mathrm{~ms}$, inflow free wall-35 \pm 11 versus $35 \pm 22 \mathrm{~ms}$, and ventriculotomy region-32 \pm 10 versus $31 \pm 16 \mathrm{~ms}$, respectively. Action potential characteristics in the ventriculotomy region of the postventriculotomy dogs were similar to a comparable region in the control animals: maximum diastolic potential- $-86 \pm 1$ versus $86 \pm 2 \mathrm{mv}$, action potential amplitude$117 \pm 3$ versus $119 \pm 3 \mathrm{mv}$, maximum velocity of phase zero upstroke-486 \pm 47 versus $543 \pm 48 \mathrm{~V} / \mathrm{s}$, and action potential duration to full repolarization-208 \pm 10 versus $208 \pm 16 \mathrm{~ms}$, respectively ( $p=\mathrm{NS})$. We conclude that 1 ) ventriculotomy-induced disruption of the subendocardial Purkinje network does not produce macroscopic conduction delay and is not a mechanism of RBBB, and 2) the homogeneous scar of a right ventriculotomy, healed under low right ventricular pressure, produces few abnormalities in action potential characteristics. (Pediatr Res 23: 433-438, 1988)
\end{abstract}

Received September 26, 1986; accepted December 17, 1987.

Reprint requests Jeffrey P. Moak, M.D., Texas Children's Hospital, Section of Pediatric Cardiology, 6621 Fannin, Houston, TX 77030.

Supported in part by Grant HL24916 from National Institutes of Health Bethesda, MD. J.P.M. is supported in part by an award from the Hartford Fellowship Program. A.G. is an established investigator of the American Heart Association, Dallas, TX.
Abbreviations

\author{
AMP, action potential amplitude \\ APD 100, action potential duration to full repolarization \\ MDP, maximum diastolic potential \\ ToF, tetralogy of Fallot \\ $\dot{V} \max$, maximum velocity of phase zero upstroke \\ VSD, ventricular septal defect \\ CT, conduction time \\ QRS, ventricular activation on the surface electrocardi- \\ ogram \\ AP, action potential \\ AV, atrioventricular
}

Right ventriculotomy is required for the surgical repair of many congenital heart defects and has been implicated as a substrate for conduction disturbances. The electrocardiographic pattern of complete right bundle branch block commonly occurs after ventriculotomy. It has been reported to occur in 60 to $100 \%$ of patients after repair of tetralogy of Fallot (1-6) and 60 to $81 \%$ of patients after surgical repair of ventricular septal defect (711).

Previous histologic and electrophysiologic studies have presented evidence that surgical injury to the right bundle may occur at any one or combination of three sites: 1) immediately after bifurcation of the bundle of His, 2) as the right bundle traverses the moderator band, and 3) at the distal subendocardial Purkinje network (12-15).

Considerable controversy exists as to the possible mechanism(s) for the conduction disturbances that occur after surgical repair of ToF or VSD. The observations of Gelband et al. (2) and Krongrad et al. (14) suggested that the electrocardiographic pattern of right bundle branch block developed after the right ventriculotomy incision, and before infundibular resection and VSD closure. Horowitz et al. (15), however, noted the development of right bundle branch block after infundibular resection in a group of patients undergoing transatrial repair of ToF.

It was the purpose of our investigation to examine the electrocardiographic and cellular electrophysiologic effects of right ventriculotomy in order to: 1) determine if disruption of the distal subendocardial Purkinje fiber network in the right ventricular free wall produced right bundle branch block and 2) assess whether abnormalities in action potential characteristics existed in or near the right ventriculotomy scar late postoperatively. 


\section{METHODS}

Surgery. Twelve beagle puppies, 6 months of age, formed the study group. After induction of anesthesia with sodium pentobarbital $(30 \mathrm{mg} / \mathrm{kg})$ intravenously and atropine sulfate $(0.01 \mathrm{mg} /$ $\mathrm{kg}$ ) intramuscularly, each animal was intubated endotracheally and ventilated with a Harvard small animal respirator. Blood gas analysis was performed intermittently and adjustments made in ventilation to keep the values within the normal range. Penicillin $\mathrm{G}, 150,000 \mathrm{U} / \mathrm{kg}$, and kanamycin, $15 \mathrm{mg} / \mathrm{kg}$, were injected intravenously.

A midline sternotomy was then performed, and the pericardium was opened. A transmural vertical ventriculotomy was performed in six puppies. The technique used was similar to that reported by Fixler and Wheeler (16) and involved making a transmural incision in the anterior right ventricular free wall two-thirds the base-apex length, approximately $4 \mathrm{~cm}$. The ventriculotomy was started in the infundibular free wall, $1-2 \mathrm{~cm}$ lateral to the left anterior descending coronary artery, and was enlarged by serial incisions. This was necessary in order to avoid the need for cardiopulmonary bypass. Each small segment of the incision involved a full thickness penetration of the right ventricular free wall into its cavity. Each segment of the ventriculotomy incision was sutured together before its length was extended. No ventriculotomy was performed on six animals; these served as the control group. The sternotomy incision was closed and the animals were allowed to recover. Each puppy, for the next 3 days, received the same dose of antibiotics as was administered preoperatively.

All animals were allowed to grow and develop to 14 months of age, 8 months postventriculotomy. When they matured to this age, each had a six lead electrocardiogram (limb leads).

Intracellular action potential measurements. Upon completion of the surface electrocardiogram, each puppy was anesthetized with sodium pentobarbital, $30 \mathrm{mg} / \mathrm{kg}$, intravenously and anticoagulated with heparin sulfate, $100 \mathrm{U} / \mathrm{kg}$, intravenously. The animals were then intubated endotracheally and ventilated with a Harvard small animal respirator. The midline sternotomy incision was reopened and all fibrous adhesions to and around the heart were lysed. The heart was quickly removed from the chest and placed in a cold oxygenated Tyrode's solution.

The right ventricle was dissected free from the left ventricle in room temperature Tyrode's solution, bubbled with $95 \% \mathrm{O}_{2}$ and $5 \% \mathrm{CO}_{2}$, by the following technique: 1) the right and left atrium were removed from the ventricles by cutting through the AV junction. 2) An incision was next made in the anterior and posterior leaflets of the tricuspid valve, allowing the right ventricular free wall to float unrestrained for chordal attachment to the papillary muscles. 3) The right ventricular posterior wall was detached from its septal connection by making an incision in the ventricle at the base of the crux and carrying it along the junction of the free wall and septum. 4) The left ventricle was opened by a vertical incision between the anterior and posterior papillary muscles. 5) The anterior-lateral and posterior-medial left ventricular free walls were then trimmed away from their septal attachments. The right ventricular preparation is illustrated in Figure $1 \mathrm{~A}$. The right ventricle was pinned to the bottom of a waxed Lucite tissue bath and superfused with Tyrode's solution containing (mmol/liter): $\mathrm{NaCl}, 131 ; \mathrm{NaHCO}_{3}, 18 ; \mathrm{CaCl}_{2}, 2.7 ; \mathrm{MgCl}_{2}$, $0.5 ; \mathrm{NaH}_{2} \mathrm{PO}_{4}, 1.8 ; \mathrm{KCl}, 4.0$; and dextrose 5.5. The tissue bath,
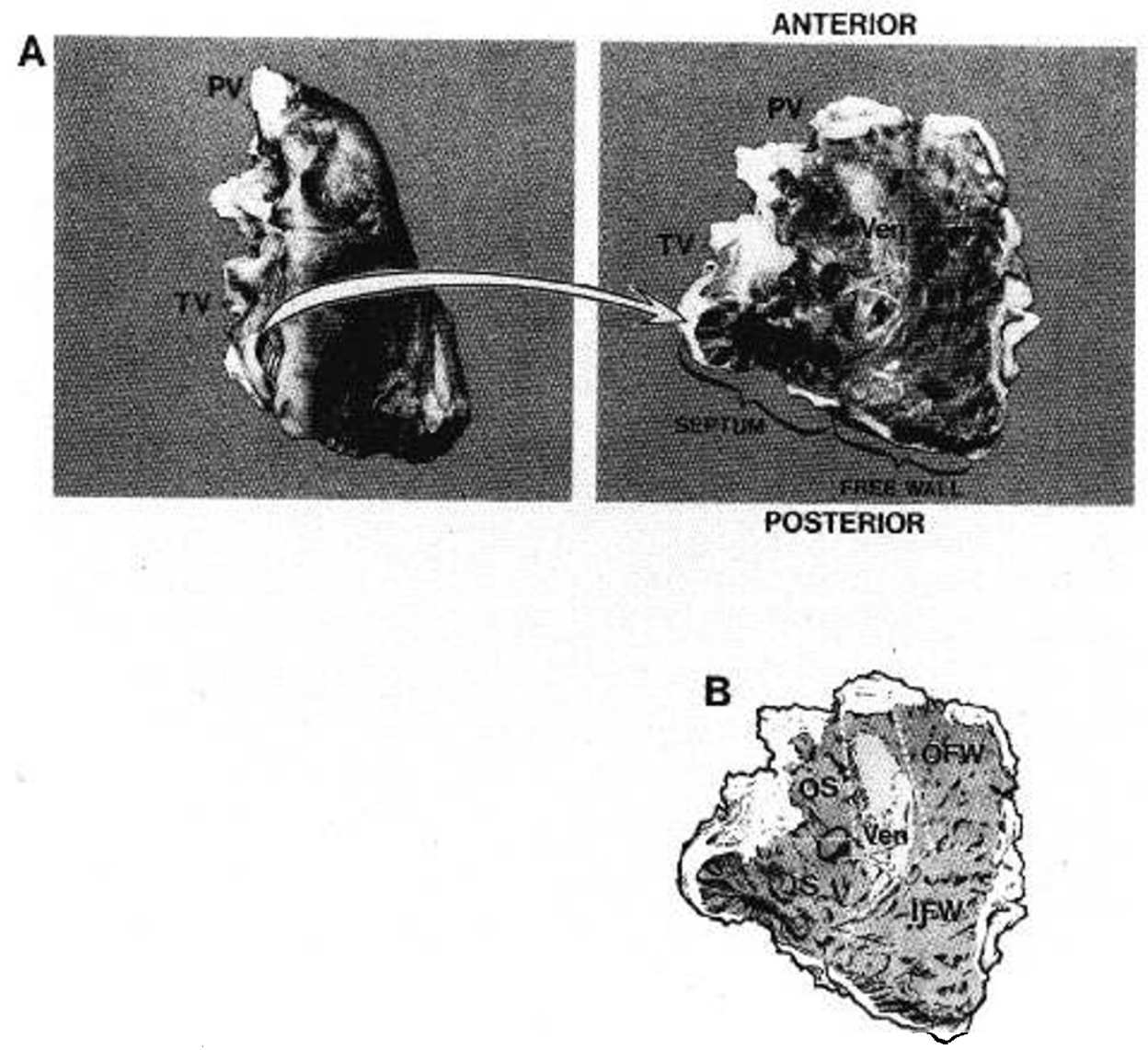

Fig. 1. Right ventricular preparation from a postventriculotomy $\operatorname{dog}$. $A$, method of dissection and display of the right ventricle preparation. The tissue specimen consisted of the right ventricular septum and free wall. The right ventricular free wall remained in continuity with the ventricular septum, anteriorly. The ventriculotomy incision was made in the anterior right ventricular free wall $1-2 \mathrm{~cm}$ lateral to the left anterior descending coronary artery and extended two-thirds the base to apex length. The black arrows outline the ventriculotomy scar. $B$, for analysis of data, the endocardial surface was subdivided into five regions: outflow septum $(O S)$, outflow free wall (OFW), inflow septum (IS), inflow free wall, (IFW), and ventriculotomy region $(V)$. $\mathrm{PV}$, pulmonary valve; TV, tricuspid valve. 
constructed with an external water jacket, maintained a minimal temperature gradient $\left( \pm 0.2^{\circ} \mathrm{C}\right)$. The Tyrode's solution was bubbled with $95 \% \mathrm{O}_{2}-5 \% \mathrm{CO}_{2}$, warmed to $37^{\circ} \mathrm{C}$, and was superfused at a rate of $26 \mathrm{ml} / \mathrm{min}$. The tissue chamber was connected to ground through a $3 \mathrm{M} \mathrm{KCl}$-silver/silver chloride junction placed $3 \mathrm{~cm}$ lateral to the tissue preparation.

The right ventricular endocardial preparation was paced at a cycle length of $500 \mathrm{~ms}$ from the proximal right bundle branch. Under low power microscopic observation, the proximal right bundle branch could be visualized, traversing the right ventricular septum toward the anterior papillary muscle. Stimuli were delivered with bipolar silver wires that were insulated to the tips with Teflon. The stimulus pulse width was $2 \mathrm{~ms}$ and the amplitude was 1.5 to 2 times diastolic threshold. The preparations were impaled with $3 \mathrm{M} \mathrm{KCl-filled} \mathrm{glass} \mathrm{capillary} \mathrm{microelectrodes}$ having tip resistances of 5-20 megohm. The following intracellular action potential characteristics were measured from photographic recordings: CT from the stimulus artifact to the mid point of the action potential upstroke, MDP, AMP, V max, which was differentiated electronically, and ADP 100.

The right ventricle was allowed to stabilize for $1 \mathrm{~h}$ before measurements were made. For each preparation, 200 to 250 microelectrode impalements of the endocardium were recorded. In an attempt to standardize the depth of microelectrode impalement, only recordings from the first through third cell layers were accepted.

Data analysis and statistical design. Twelve beagle dogs made up the two study groups used for these experiments. Group I was a control group of six dogs which had all procedures except right ventriculotomy. The six group II dogs had a right ventriculotomy procedure.

To facilitate constructing an endocardial map of right ventricular activation, an 8 by 10 inch sketch of the right ventricular preparation was made. An overlying twenty-six by twenty coordinate grid allowed localization of the site of impalement for data analysis.

The microelectrode data from each right ventricular preparation was separated into five regional groups: outflow septum, inflow septum, outflow free wall, inflow free wall, and ventriculotomy region (Fig. $1 B$ ). For each animal, a regional mean of action potential characteristics was obtained by averaging all action potential data within a specific region. Thus, for each animal, five regional means were calculated. To detect regional differences that might exist within either the control group or experimental group, the regional mean from each of the six group animals was then averaged. Statistical significance of differences within either group I or II was assessed by one-way analysis of variance. If the overall analysis of variance revealed statistical significance among the regions $(p<0.05)$, then individual $t$ tests were performed, using Bonferonni's modification of the $t$ test (17). A nested analysis of variance was performed to assess the statistical significance of differences that might exist between groups I and II. If the nested analysis of variance revealed a statistically significant difference between groups I and II, then pairwise comparisons of similar regions were performed using Bonferonni's modification. The statistical probability of differences are reported in the text. An unpaired $t$ test was used for the statistical comparison of differences in QRS duration between groups I and II. The results given in the text are expressed as the mean $\pm \mathrm{SD}$.

\section{RESULTS}

Late electrocardiographic sequelae. No significant changes were apparent on the surface electrocardiogram in the immediate and late $(8$ months) postoperative periods after right ventriculotomy. The QRS duration (lead II) for the ventriculotomy group was $34 \pm 7 \mathrm{~ms} 8$ months after surgery. This was not significantly different from the control group, $34 \pm 4 \mathrm{~ms}$. In none of the postventriculotomy dogs did the surface QRS morphology simulate a right bundle branch block pattern.
Late electrophysiologic sequelae. Endocardial Activation. To assess whether right ventriculotomy produced delayed regional activation without prolongation of the surface $\mathrm{QRS}$, the sequence of right ventricular endocardial activation was mapped. Moderate delays in regional activation may occur with a normal surface QRS duration if the area of delay is activated early in the process of ventricular excitation, normally. Illustrated in Figure 2 is an isochronal map of RV endocardial activation from a control dog. Conduction spread in less than $20 \mathrm{~ms}$ from the proximal right bundle branch, the site of pacing, to the anterior papillary muscle. Activation then spread centrifugally from the right ventricular apex. Activation of the right ventricular free wall was completed by $39 \mathrm{~ms}$ after the initiation of excitation. The posterior-basal right ventricular septum was the last region to be activated, $49 \mathrm{~ms}$ after initiation of pacing.

Right Ventriculotomy: Structural-Functional Correlations. Transection of all free running branches of the distal Purkinje fiber network, aborizing from the base of the anterior papillary muscle, was never produced by our vertical ventriculotomy incision. Surgery injured either the septal or anterior fascicle alone in two of six postventriculotomy animals.

Right ventricular endocardial activation in the post-ventriculotomy group was similar to the control group (Fig. 3). No differences in region activation could be demonstrated between control and post ventriculotomy animals (Table 1).

Delayed epicardial activation of the lateral right ventricular outflow tract and posterior-basal right ventricular free wall has been observed after ventriculotomy in ToF patients with right bundle branch block $(2,15)$. In our canine studies, no delay of activation of the right ventricular free wall could be demonstrated in the postventriculotomy group. Activation of the anterior papillary muscle region occurred $18 \pm 5$ and $20 \pm 4 \mathrm{~ms}$ after initiation of pacing from the proximal right bundle branch in groups I and II, respectively ( $p=\mathrm{NS}$ ). As mentioned previously, the central component of the right bundle branch could be visualized on the septal surface, running from the base of the

\section{CONDUCTION TIME}

CONTROL

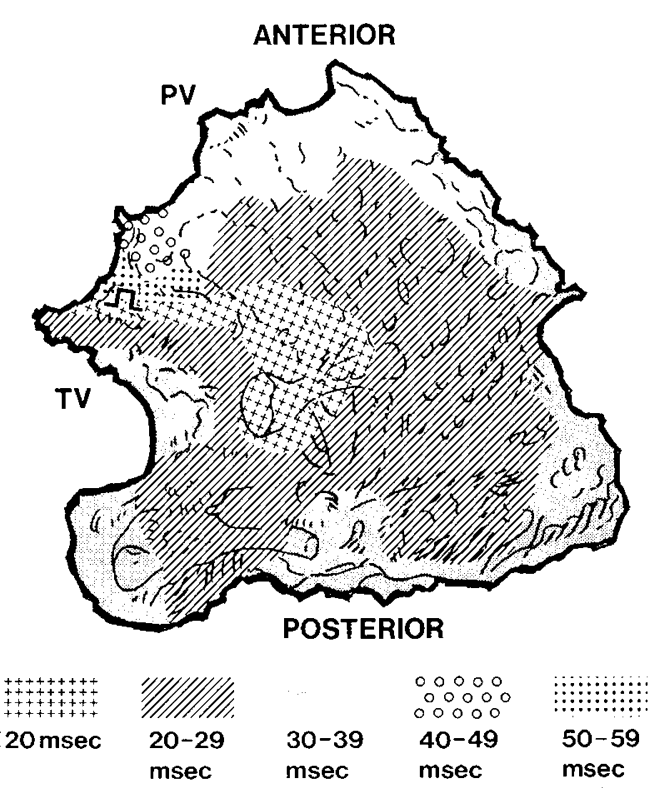

Fig. 2. Sequence of right ventricular endocardial activation in a control dog. Activation proceeded rapidly along the right bundle branch to the right ventricular apex, from which it spread centrifugally. Excitation of the right ventricular free wall was completed by $39 \mathrm{~ms}$. The superior right ventricular septum, in the region of the papillary muscle of the conus, was last to be activated. $\Omega$, pacing site. 


\section{CONDUCTION TIME}

RIGHT VENTRICULOTOMY

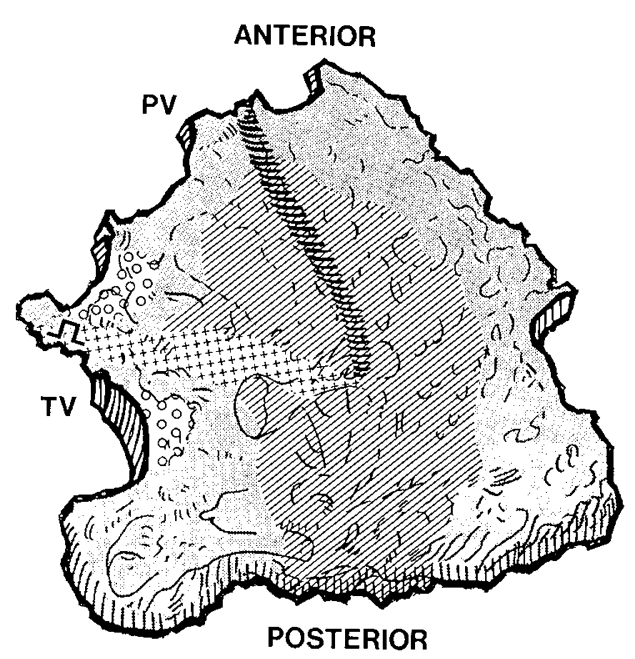

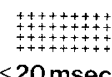
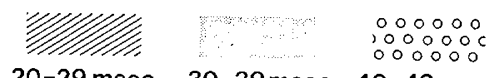

$30-39 \mathrm{msec} \quad 40-49 \mathrm{msec}$

Fig. 3. Sequence of right ventricular endocardial activation of a postventriculotomy dog. Activation proceeded rapidly from the proximal right bundle branch to the anterior papillary muscle. Once activated, excitation proceeded from the apex to the base. The right ventricular free wall was completely activated by $39 \mathrm{~ms}$. The superior basal right ventricular septum was activated last. No macroscopic delay of conduction across the ventriculotomy region was evident. $\equiv$, ventriculotomy incision; $\Omega$, pacing site.

Table 1. Comparison of differences in regional activation between control and postventriculotomy animals

\begin{tabular}{|c|c|c|c|c|c|}
\hline \multirow[b]{2}{*}{ Experimental group } & \multicolumn{5}{|c|}{ Regional activation (ms) } \\
\hline & $\begin{array}{l}\text { Outflow } \\
\text { septum }\end{array}$ & $\begin{array}{l}\text { Inflow } \\
\text { septum }\end{array}$ & $\begin{array}{c}\text { Outflow } \\
\text { free } \\
\text { wall }\end{array}$ & $\begin{array}{l}\text { Inflow } \\
\text { free } \\
\text { wall }\end{array}$ & $\begin{array}{l}\text { "Ventricu- } \\
\text { lotomy" } \\
\text { region }\end{array}$ \\
\hline Control $(n=6)$ & $36 \pm 16$ & $33 \pm 13$ & $38 \pm 13$ & $35 \pm 22$ & $31 \pm 16$ \\
\hline $\begin{array}{l}\text { Postventriculotomy } \\
\quad(n=6)\end{array}$ & $30 \pm 16$ & $32 \pm 7$ & $33 \pm 10$ & $35 \pm 11$ & $32 \pm 10$ \\
\hline
\end{tabular}

right ventricle to the anterior papillary muscle. The presence of rapid conduction and healthy action potentials along its course confirmed the absence of electrical damage to the proximal right ventricular conduction system. Conduction from the anterior papillary muscle to the outflow free wall averaged $19 \pm 6$ and 16 $\pm 5 \mathrm{~ms}$ in groups I and II, respectively $(p=\mathrm{NS})$. Similarly, the conduction time from the anterior papillary muscle to the inflow free wall did not differ between groups I and II, $17 \pm 7$ and 16 $\pm 6 \mathrm{~ms}$.

Propagation in the Ventriculotomy Region. Activation was carefully mapped in the ventriculotomy region. Within the ventriculotomy region, conduction appeared to occur preferentially through the free running Purkinje network (Fig. $4 A$ ). The anterior and posterior fascicles of the distal Purkinje fiber network are the structures depicted as being activated in $<20 \mathrm{~ms}$. Similar observations were made in all the experiments performed.

Although no regional delays of activation were apparent, localized areas of conduction delay and block were noted within the ventriculotomy scar. Conduction delays of 10 to $30 \mathrm{~ms}$ were sometimes found over distances no longer than 0.5 to $2 \mathrm{~mm}$. Figure $4 A$ demonstrates an expanded isochronal map of endocardial activation of the ventriculotomy scar from the right ventricular preparation illustrated in Figure 3. A 10-ms delay of activation was apparent at the posterior-inferior edge of the ventriculotomy site in this preparation.

No action potentials could be recorded from $51 \%$ of impalements in the center of the ventriculotomy scar. In most of the failed impalements, no cellular activity could be recorded. Rarely, regions of high level conduction block were observed (Fig. 4B).

Comparison of AP Characteristics in the "Ventriculotomy" Region from Control and Postventriculotomy Animals. The AP characteristics in the "ventriculotomy" region of the control and postventriculotomy animals were similar and did not differ statistically: MDP - group I ( $-86 \pm 2 \mathrm{mv})$ versus group II (-86 \pm $1 \mathrm{mv})$; AP amplitude-group I $(119 \pm 3 \mathrm{mv})$ versus group II $(117 \pm 3 \mathrm{mv}) ; \dot{V} \max$-group I $(543 \pm 48 \mathrm{~V} / \mathrm{s})$ versus group II $(486 \pm 47 \mathrm{~V} / \mathrm{s})$; and APD 100-group I $(208 \pm 16 \mathrm{~ms})$ versus group II (208 $\pm 10 \mathrm{~ms})$.

\section{DISCUSSION}

Right bundle branch block has been noted to occur in 60 to $100 \%$ of patients undergoing surgical repair of ToF (18). The long-term prognostic significance of this electrocardiographic pattern is thought to be benign (18); however, the development of acquired left bundle branch block may predispose to complete AV block if the right bundle injury is "central." Acquired complete AV block has been documented to occur after surgically induced left bundle branch block was added to a preexisting right bundle branch block (19). Of concern is whether acquired complete AV block will develop in postoperative ToF patients who develop atherosclerotic left bundle branch block.

The clinical observations of Gelband et al. (2) and Krongrad et al. (14) have suggested that the electrocardiographic pattern of right bundle branch block developed immediately after the right ventriculotomy incision. Because there was no associated injury to the ventricular septum with this incision, thereby excluding the possibility of central injury to the right bundle branch, the authors deduced that there was "peripheral" injury to the right bundle branch. Krongrad et al. (14) suggested that the conduction defect was distal to the insertion of the terminal fascicles of the right bundle into the ventricular myocardium. The prognostic significance of "peripheral" right bundle branch block would thus be excellent because conduction through the proximal right bundle branch and its terminal fascicles would be normal. However, the prognostic significance would be guarded if the site of injury was more central.

The results of our study suggested that vertical ventriculotomy of the anterior free wall of the right ventricle does not produce "peripheral" right bundle branch block. No electrocardiographic evidence of right bundle branch block was noted in the dogs subjected to right ventriculotomy. QRS duration and morphology were similar in the control and postventriculotomy animals. No regional delay in activation of the right ventricular inflow or outflow free wall was demonstrated during proximal right bundle branch pacing in our in vitro experiments. Conduction delay and block was evident at a microscopic leve (Fig. 4); but macroscopically, no regional conduction delay developed after right ventriculotomy because of alternate pathways for rapid conduction.

How then does right ventriculotomy produce right bundle branch block? The surgical experiments of Uhley and Rivkin (20) and Genender et al. (2) demonstrated that there is little change in the QRS duration or epicardial activation sequence if conduction through the terminal free running Purkinje fibers was interrupted individually. However, Hill et al. (22) found the QRS duration to become prolonged and activation of the posterior-basal right ventricle and right ventricular outflow tract to 


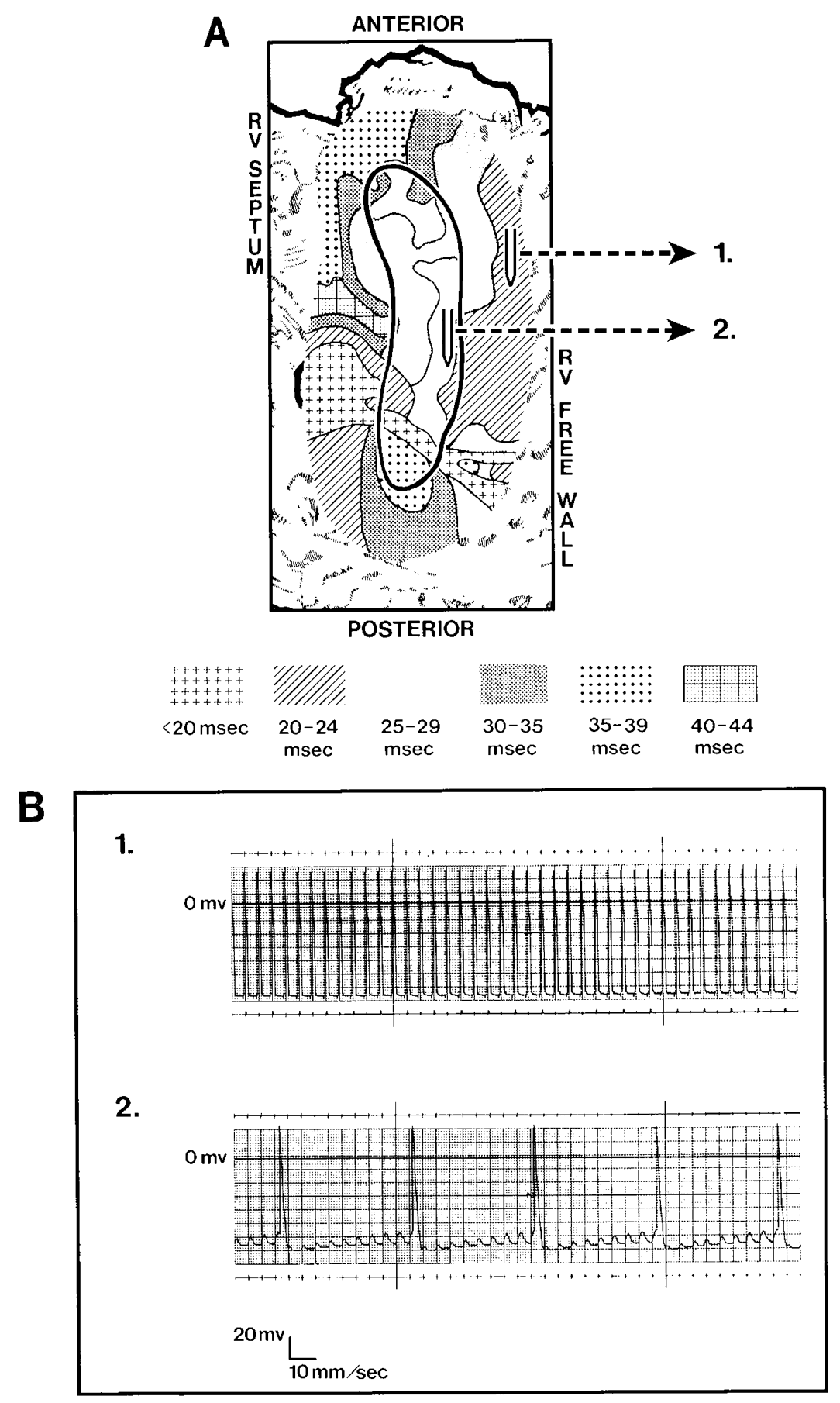

Fig. 4. Isochronal map of right ventricular activation in the ven-triculotomy region. $A$, activation spread rapidly along the edges of the ventriculotomy scar. Excitation of the "ventriculotomy" region appeared as if there were two wave fronts simultaneously activating the medial and lateral borders of the scar. Centrally, no action potentials could be recorded from the superficial cell layer. Rarely, cellular activity was observed from cells deep within the scar. Conduction delay $(10-15 \mathrm{~ms})$ was evident at the posterior-medial edge of the ventriculotomy scar. Oval outlined by black line represents the ventriculotomy scar. $\equiv$, site of microelectrode impalement. $B$, example of high level conduction block into the central ventriculotomy scar. Two simultaneous microelectrode impalements of the ventriculotomy region were recorded: one at the border of "healthy" tissue and the ventriculotomy scar; and the second, centrally, within the ventriculotomy scar. The proximal right bundle branch was paced at a cycle length of $500 \mathrm{~ms}$. The superior-lateral border of the ventriculotomy scar was activated 20 to $24 \mathrm{~ms}$ after initiation of the paced beat. One-to-one conduction into this region was evident. In the center of the ventriculotomy scar, high level conduction block occurred. Time and voltage calibration appear at the bottom of the figure.

become delayed by 16 to $39 \mathrm{~ms}$ if the terminal free running Purkinje fibers were sectioned conjointly. Collectively, these experiments suggest that transaction of all three terminal fascicular divisions of the distal right bundle could delay activation of the right ventricular free wall and produce "right bundle branch block." Sectioning of a single fascicle would be without effect. These results are not unlike those found herein. The surgically produced vertical ventriculotomy occasionally tran- 
sected one of the fascicles of the distal Purkinje fiber network, but never all of them.

The moderator band is the human equivalent to the distal terminal divisions of the right bundle branch in the canine heart (23). Surgical division of the moderator band at the time of right ventriculotomy may produce "peripheral" right bundle branch block and is consistent with the clincal observations of Krongrad et al. (14). These investigators noted that ventriculotomy induced right bundle branch block was not related to the total length of the incision or to the order in which the incision was made. Conduction delay occurred when an incision was made at a specific site in the right ventricular free wall.

The location of the site of conduction delay that produces "peripheral" right bundle branch block is currently unknown. Our experimental results demonstrate that right ventriculotomy induced disruption of the peripheral subendocardial Purkinje network does not produce any macroscopic distal conduction delay. These results suggest that the site of conduction delay has to be more proximal in the right ventricular conduction system.

Limitations of experimental design. The experiments reported herein were performed on previously normal dogs with nonhypertrophied hearts. Many similarities in the conduction system of the canine and human heart exist, but so do differences in the anatomy and morphology of the peripheral divisions of the right and left bundle branches (23). Experimental evidence suggests that differences between the endocardial Purkinje and ventricular myocardial cells in the human left ventricle may be more subtle than that observed in the dog (24). Even less is known about the endocardial surface of the human right ventricle. The electrophysiologic effects of right ventriculotomy on cardiac conduction in the right ventricle observed herein are applicable to the human situation only in so far as the subendocardial region of the human right ventricle resembles its canine counterpart.

Although macroscopic conduction delay was not evident, our microelectrode studies demonstrated the presence within the ventriculotomy scar of small localized areas of slow conduction and delayed activation. All recorded action potentials from the area of delayed activation had normal resting membrane potentials and rapid upstroke velocities, suggesting that depolarization was generated by the fast inward sodium current. This is in contrast to what has been thought to be the usual mechanism for slow conduction, i.e. action potentials dependent on the slow inward calcium current (25). Recent studies by Spach et al. (26) have pointed out the importance of cardiac muscle structure in influencing the propagation of a depolarizing wave front. The absence of slow response action potentials within the ventriculotomy region suggests that alterations of the basic cell membrane properties were not responsible for the slow conduction demonstrated. However, alterations in cell coupling, either at the cell to cell level or muscle bundle to muscle bundle level, can significantly depress propagation velocity, even though depolarization occurs through the fast inward sodium current (normal action potentials) (27). Understanding the functional alterations of conduction within the ventriculotomy scar on a microscopic level was beyond the scope of the experiments designed for this study. Ultimately, these experiments will be important to perform in order to understand possible mechanisms for the ventricular arrhythmias that occur in postoperative ventriculotomy patients.

Implications of study. The results herein suggest that in our canine model right ventriculotomy-induced right bundle branch block is not secondary to disruption of the subendocardial Purkinje network in the free wall. This observation implies that the site of conduction delay should be more central along the right ventricular conduction system. If the site of block is proximal to the myocardial insertion of the terminal fascicles of the right bundle, then complete AV block may develop if acquired left bundle branch block is superimposed on even this type of right bundle branch block.
Acknowledgments. The authors acknowledge with gratitude the technical assistance of Gregory Clark and Kathy Sprague; and the secretarial assistance of Terri Woods.

\section{REFERENCES}

1. Landtman B, Wolf MD 1965 Total correction of tetralogy of Fallot. II. Changes in the electrocardiogram following surgery. Circulation 31:394-402

2. Gelband $\mathrm{H}$, Waldo AL, Kaiser GA, Bowman FO, Malm JR, Hoffman BF 1971 Etiology of right bundle branch block in patients undergoing total correction of tetralogy of Fallot. Circulation 44:1022-1033

3. Wolf GS, Rowland TW, Ellison RC 1972 Surgically induced right bundle branch block with left anterior hemiblock: an ominous sign in post-operative tetralogy of Fallot. Circulation 46:587-594

4. Garson A, Nihill MR, McNamara DG, Cooley DA 1979 Status of the adult and adolescent following repair of tetralogy of Fallot. Circulation 59:12321240

5. Deanfield JE, McKenna WJ, Hallidie-Smith KA 1980 Detection of late arrhythmia and conduction disturbance after correction of tetralogy of Fallot. Br Heart J 44:248-253

6. Fuster V, McGoon DC, Kennedy MA 1980 Long term evaluation (12 to 22 years) of open heart surgery for tetralogy of Fallot. Am J Cardiol 46:635642

7. Bristow JD, Kasselbaum DG, Starr A, Griswold HE 1960 Observations on the occurrence of right bundle branch block following open repair of ventricular septal defects. Circulation 22:896-900

8. Fisher JM, Theilen EO, January LE, Ehrenhaft JL 1960 Electrocardiographic sequelae of right ventriculotomy in patients with ventricular septal defects. Circulation 22:280-288

9. Kulbertus HE, Coyne JJ, Hallidie-Smith KA 1969 Conduction disturbances before and after surgical closure of ventricular septal defect. Am Heart J $77: 123-131$

10. Okoroma EO, Guller B, Maloney JD, Weidman WH 1975 Etiology of right bundle branch block pattern after surgical closure of ventricular septal defects. Am Heart J 90:14-18

11. Boxer R, Krongrad E, Bowman FO, Malm JR, Gersony WM 1977 Conduction defects following ventricular septal defect closure with and without a right ventriculotomy. Pediatr Res 11:386(abstr)

12. Titus JL, Daugherty GW, Kirklin JW, Edwards JE 1963 Lesions of the atrioventricular conduction system after repair of ventricular septal defect: relation to heart block. Circulation 28:82-88

13. Lev M, Fell EH, Arcilla R, Weinberg MH 1964 Surgical injury to the conduction system in ventricular septal defect. Am J Cardiol 14:464-476

14. Krongrad E, Hefler SE, Bowman FO, Malm JR, Hoffman BF 1974 Further observations on the etiology of right bundle branch block pattern following right ventriculotomy. Circulation 50:1105-1113

15. Horowitz LN, Simson MB, Spear JF, Josephson ME, Moore EN, Alexander JA, Kastor JA, Edmunds LH 1979 The mechanism of apparent right bundle branch block after transatrial repair of tetralogy of Fallot. Circulation 59:1241-1252

16. Fixler DE, Wheeler JM 1980 Dopamine infusion following ventriculotomy in dogs with right ventricular hypertrophy. Pediatr Res 13:343-348

17. Wellenstein S, Zucker C, Fleiss JL 1980 Some statistical methods useful in circulation research. Circ Res 47:1-12

18. Krongrad E 1978 Prognosis of patients with congenital heart disease and postoperative intraventricular conduction defects. Circulation 57:867-870

19. Krongrad E, Bharati S, Steinfeld L, Lev M 1977 Histologic observations of the cardiac conduction system in a heart with postoperative bilateral bundle branch block. Am J Cardiol 40:635-640

20. Uhley H, Rivkin L 1961 Electrocardiographic patterns following interruption of main and peripheral branches of the canine right bundle of His. Am J Cardiol 7:810-816

21. Genender LJ, Stuckey JH, Jomain SL, Hoffman BF 1963 Effects of right ventriculotomy upon activation of the epicardial surface of the canine right ventricle. Circulation 27:828-834

22. Hill JD, Moore EN, Patterson DF 1968 Ventricular epicardial activation studies in experimental and spontaneous right bundle branch block in the dog. Am J Cardiol 21:232-240

23. Esmond WG, Moulton GA, Crowley RA, Attar S, Blair E 1963 Peripheral ramifications of the cardiac conduction system. Circulation 27:732-738

24. Dangman KH, Danilo P, Hordof AJ, Mary-Rabine L, Reder RF, Rosen MR 1982 Electrophysiologic characteristics of human ventricular and Purkinje fibers. Circulation 65:362-368

25. Spear JF, Horowitz LN, Moore EN 1980 The slow response in human ventricle. In: Zipes DP, Bailey JC, Elharrar V (eds) The Slow Inward Current and Cardiac Arrhythmias. Martinus Nijhoff, The Hague, pp 309-326

26. Spach MS, Miller WT, Dolber PC, Kootsey M, Sommer JR, Mosher CE 1982 The functional role of structural complexities in the propagation of depolarization in the atrium of the dog. Cardiac conduction disturbances due to discontinuities of effective axial resistivity. Circ Res 50:175-191

27. Spach MS, Dolber PC 1986 Relating extracellular potentials and their derivations to anisotropic propagation at a microscopic level in human cardiac muscle. Evidence for electrical uncoupling of side to side fiber connections with increasing age. Circ Res 58:356-371 